\title{
Psicologia na Saúde: Sociopsicológica ou Psicossocial? Inovações do Campo no Contexto da Resposta Brasileira à Aids
}

\author{
Vera Silvia Facciolla Paiva ${ }^{\mathbf{1}}$ \\ Departamento de Psicologia Social e do Trabalho da Universidade Estadual de São Paulo, \\ São Paulo, Brasil
}

\section{Resumo}

Uma revisão crítica da literatura sobre os usos e o sentido do termo psicossocial em periódicos brasileiros inicia este texto. Discutirá, em seguida, como a concepção brasileira do "modo psicossocial" na atenção ao sofrimento mental, produzida no movimento pela reforma sanitária dos anos 1980, contribuiu para constituir um campo de estudos e práticas inovador, desenvolvido centralmente no contexto da resposta brasileira à Aids. Reconhecida internacionalmente, mas pouco conhecida na intimidade, a perspectiva baseada nos direitos humanos e de análise no quadro da vulnerabilidade (social, programática e individual) produziu uma vertente da psicologia social construcionista na saúde que se define como psicossocial e não sociopsicológica. As técnicas e processos de trabalho derivados desta abordagem da vulnerabilidade e dos direitos humanos (V\&DH) se distinguem pela valorização da mediação programática e, portanto, da ação pela proteção ou para mitigação da violação de direitos. Distinguem-se, ainda, pela abordagem necessariamente psicossocial das práticas nos diversos níveis e territórios de atenção e prevenção. Inspirada pela hermenêutica e pelo construcionismo social, essa vertente da psicologia social construcionista priorizará a compreensão da "intersubjetividade em cena" implicada em cenários socioculturais - nos encontros programáticos em serviços focalizará cenas cotidianas e da trajetória da pessoa. A noção de pessoa, tomada como sujeito de discursos e de direitos, contrasta com a noção de individuo biológico-comportamental da psicologia da saúde que permaneceu nos paradigmas para pensar o processo saúde-doença. Este artigo oferecerá, portanto, referências para uma reflexão crítica sobre o contexto histórico e acadêmico da produção no campo da Aids incluída neste suplemento.

Palavras-chave: Psicologia Social, direitos humanos, vulnerabilidade, construcionismo, promoção da saúde.

Endereço para correspondência: Departamento de Psicologia Social e do Trabalho, Instituto de Psicologia, Universidade de São Paulo, Av. Prof. Mello Moares, 1721, Cidade Universitária, São Paulo, SP, Brasil 05508900. E-mail: veroca@usp.br

Agradecemos o apoio da Fundação Ford, que nos convidou a sistematizar e, em seguida, a traduzir a produção que há mais de duas décadas nos distingue como grupo ativo na resposta à Aids. Para a produção e edição deste suplemento, contei com o incentivo da bolsa PQ/CNPq (Produtividade em Pesquisa/Conselho Nacional de Desenvolvimento Científico e Tecnológico), que valoriza minha dedicação à pesquisa e permite a coordenação das atividades do NEPAIDS (Núcleo de Estudos para a Prevenção da Aids da Universidade de São Paulo). Este suplemento não teria sido possível sem o companheirismo e alegria no trabalho dos colegas da rede que compõe o NEPAIDS, da equipe da revista e do trabalho rigoroso dos pareceristas. 


\title{
Social Psychology and Health: Socio-Psychological or Psychosocial? Innovation of the Field in the Context of the Brazilian Responses to AIDS
}

\begin{abstract}
A critical review of the literature on the uses and meanings of the expression psychosocial in Brazilian journals opens this text. It will discuss how the Brazilian notion of "psychosocial mode" to organize mental health care, framed within the health reform movements in the 1980s, contributed to the formation of a field of studies and innovative practices, developed mostly in the context of the Brazilian response to AIDS. Its human rights perspective is unknown in its details as well as its constructionist approach to health psychology defined as psychosocial rather than socio-psychological, distinguished also by a psychosocial approach at the various levels and territories of prevention and care practices. The techniques and work processes derived from a unique Brazilian vulnerability and human rights approach (V\&HR) value the programmatic mediation of the inextricably linked social and individual vulnerability and, therefore, actions for mitigation of rights violations. Strongly inspired by hermeneutics and the social sciences constructivism, this approach to constructionist social psychology prioritize the comprehension of "inter-subjectivity in scene", understood as intrinsically related to socio-cultural scenarios - approached in programmatic encounters at health services through personal trajectory and everyday life scenes. The notion of person, taken as a subject of discourses and holder of rights, contrasts with the notion of a biological-behavioral individual of the health psychology tradition that remained active in other paradigms of health-disease processes. This article will provide references for a critical reflection on the historical and scholarly production in the field of AIDS included in this supplement.
\end{abstract}

Keywords: Social Psychology, human rights, vulnerability, constructionism, health promotion.

\section{Psicología en la Salud: Sociopsicológica o Psicosocial? La Innovación en el Contexto de la Respuesta Brasilera al SIDA}

\section{Resumen}

Este texto inicia con una revisión crítica de la literatura sobre los usos y el sentido del término psicosocial en periódicos brasileros. Discutirá cómo la concepción brasilera del "modo psicosocial" en la atención al sufrimiento mental, producida desde el movimiento por la reforma sanitaria, contribuyó para constituir un campo de estudios y prácticas innovador, desarrollado en el contexto de la respuesta brasilera al Sida. La perspectiva vulnerabilidad y derechos humanos (V\&DH), poco conocida en la intimidad, basada en los derechos humanos y en la análisis de la vulnerabilidad (social, programática e individual) produjo una vertiente de la psicología social construccionista en la salud que se define como psicosocial y no socio psicológica. Se distingue por abordajes psicosociales de las prácticas en diversos niveles y territorios de atención y prevención. Las técnicas y procesos de trabajo de este abordaje de la vulnerabilidad, destacan la mediación programática y, efectivamente, de la mitigación de la violación de derechos. Inspirada por la hermenéutica y por el construccionismo social, esta vertiente de la psicología social construccionista priorizará la comprensión de la "intersubjetividad en escena" implicada en escenarios socioculturales - en los encuentros programáticos en servicios focalizará escenas cotidianas y de la trayectoria de la persona. La noción de persona, concebida como sujeto de discursos y de derechos, contrasta con la noción de individuo biológico-comportamental de la psicología de la salud que permaneció en otros paradigmas sobre procesos salud-enfermedad. Este artículo ofrecerá referencias para una reflexión crítica sobre el contexto histórico y académico de la producción incluida en este suplemento.

Palabras clave: Psicología social, derechos humanos, vulnerabilidad, constructivismo, promoción de la salud. 
Há um saber operante na prática que é fundamental para produzir sua renovação. Se desde a prática não nos dedicamos a teorizar, desperdiçamos o trabalho humano da reflexão. A emergência da epidemia da Aids nos anos 1980 foi, sem dúvida, um estímulo para inovação de práticas, técnicas e teorias implicadas no desafio de abordar as dimensões sociais e psicossociais em processos saúde-doença.

Elogiada internacionalmente por expandir abordagens individualistas, considerar o contexto social e por adotar políticas na perspectiva da defesa e promoção de direitos humanos, a chamada "resposta brasileira à Aids", um conjunto de programas e práticas organizadas de modo pioneiro desde os anos 1980, foi renovadora (Berkman, Garcia, Muñoz-Laboy, Paiva, \& Parker, 2005; Kerrigan et al., 2013; Nunn, da Fonseca, Bastos, \& Gruskin, 2009; Paiva, 2002). Vários autores discutem o quanto ela dependeu da ativa articulação entre pesquisadores, atores governamentais e na sociedade civil que organizaram intervenções estruturais e institucionais antes mesmo da existência do SUS (Sistema Único de Saúde), como se pode ler no artigo sobre a resposta religiosa deste suplemento. Tem sido inspiração para outros países. A produção de informação rigorosa que, ao mesmo tempo em que monitora com ciência as várias faces da epidemia, conta com a participação de pessoas afetadas diretamente pela Aids, distingue-a da resposta a várias outros males endêmicos no Brasil. Seu mais notável sucesso foi a organização de uma rede de serviços de saúde articulados intersetorialmente que, orientados pelos princípios do SUS, têm oferecido o acesso universal e gratuito à testagem e ao tratamento integral aos que são diagnosticados com a infecção pelo HIV, assim como à prevenção centrada no preservativo (Berkman et al., 2005; Greco \& Simon, 2007; Malta \& Beyrer, 2013; Paiva, 2002).

É intuitivo reconhecer que essas ações dependeram fortemente de abordagens psicossociais que, como veremos, estão inspiradas na tradição das ciências humanas e sociais aplicadas, especialmente, ao adoecer e à sexualidade e integradas nas práticas em saúde baseadas nos direitos humanos (Gruskin \& Tarantola, 2008, 2012; Kalichman \& Diniz, 2009; Kerrigan et al., 2013;
Nunn et al., 2009; Paiva, 2002, 2008, 2012a). Como retomam vários artigos deste suplemento, as práticas psicoeducativas e de aconselhamento no âmbito das frentes mais bem sucedidas da resposta à Aids no Brasil garantiram a capacitação permanente de profissionais e vários setores (saúde, educação, justiça, assistência social, nas empresas), investiram na compreensão e mitigação do processo de estigmatização e discriminação, valorizaram uma interação profissional-paciente e serviço-usuário que consegue apoiar a adesão à medicação e ao preservativo, com resultados comparáveis aos países mais ricos do hemisfério norte.

Muitas dessas práticas são resultantes de uma produção brasileira sobre as dimensões psicossociais do processo saúde-doença, cujos autores nem sempre são psicólogos. Essa produção, teórica e prática, é pouco conhecida internacionalmente e merece atenção especial de outros campos temáticos e disciplinares. A disseminação mais organizada desta produção tem ampliado a qualidade da resposta a outros agravos de saúde - doenças sexualmente transmissíveis, abuso de álcool e drogas, excesso de peso tuberculose e hepatites virais - e respondido ao desafio da humanização das práticas em saúde no campo da saúde da mulher e da criança.

Este texto oferecerá algumas referências para uma reflexão crítica sobre o contexto histórico e acadêmico desta produção e, em especial, para o sentido do termo psicossocial adotado neste caminho.

\section{O Uso do Termo Psicossocial}

A "(baixa) qualidade da atenção psicossocial"2 e a necessidade de (maior) "atenção aos usuários em risco psicossocial" ${ }^{3}$ são ponderações frequentes de textos no campo da atenção em saúde. Nos documentos institucionais que organizam programas e políticas públicas de saúde, esta expressão indica largos princípios para a ação, no bom sentido de defender o prin-

2 Psicossocial care é o termo mais frequente em inglês.

3 Em vários documentos do Ministério da Saúde do Brasil (2008). 
cípio da integralidade que privilegia o cuidar e amplia uma clínica tradicionalmente reduzida ao tratar. Entre os artigos disponíveis na literatura mais acadêmica, poucos definem precisamente o sentido do termo psicossocial ou do domínio psicossocial a se abordar. Mais raramente ainda, essa literatura dedica-se a descrever a intimidade dessas práticas e os detalhes dos processos de trabalho que poderiam ser adotados nessa direção.

Não é uma tarefa simples: afirmar a dimensão psicossocial é integrar domínios por muito tempo tratados de modo separados na formação profissional - o social do individual, a sociedade da pessoa. Trata-se de dar conta do hífen em psico-social ${ }^{4}$, o sinal que indica uma ligação entre palavras compostas e abolido na reforma ortográfica da língua portuguesa. ${ }^{5}$ Alguns autores de língua inglesa no campo psi o defendem na medida em que significaria, ao mesmo tempo, a irredutibilidade da dimensão psicológica à social (e vice-versa) e a impossibilidade de um domínio existir sem o outro: são complementares. A manutenção do hífen traduziria uma insistência na diferença, "uma diferença que não pode ser superada e que continuamente convida ao engajamento e à exploração" (Hogget, 2008, p. 13).

Como o termo psicossocial aparece em português e nas mais acessadas bases de dados de literatura disponível eletronicamente? Embora seja recuperado em numerosos artigos, livros e teses $^{6}$, psicossocial não consta como um descritor, é encontrado apenas como adjetivo asso-

4 O debate sobre o hifen foi iniciado no Depto. de Psicologia Social da Universidade de São Paulo pelas colegas Belinda Mandelbaum, Luiz Galeão e Nelson da Silva Júnior em um documento interno não publicado de 2011, a quem devo a inspiração.

5 O tradutor deste texto em inglês e espanhol nota que o hífen é utilizado quando a palavra é usada como adjetivo (socio-psychological em inglês mas sociopsicología em espanhol). A separação por espaço entre as palavras é usada quando se refere ao substantivo, também em inglês e espanhol (social psychology, psicología social).

6 Em agosto de 2013, recuperamos com o termo psicossocial 841 artigos no scielo.br, 390 na BVS e mais 218 teses e 40 livros. ciado a outros unitermos. Não é um descritor na BVS-Psi ULAPSI (Biblioteca Virtual em Saúde-Psicologia), a referência latina americana sediada no Brasil, dedicada à atualização profissional do psicólogo e ao avanço da pesquisa em psicologia. Também não aparece como terminologia em ciências da saúde (DeCS), utilizada no SciELO. Quando a fonte utilizada é a APA (American Psychological Association), encontramos o termo psicossocial qualificando "reabilitação" (cognitiva, física, de abuso de drogas) ou associado ao "desenvolvimento psicossocial" que pode ser utilizado como sinônimo de "desenvolvimento social" quando tem como referência a obra de Erick Erikson. Para pensar o caráter da produção brasileira, quando a fonte do termo é a $\mathrm{SBD}^{7}$ brasileira, o encontramos associado ao unitermo "Centro de Atenção Psicossocial" ou "intervenção psicossocial". Na terminologia de saúde, nem como adjetivo é possível ser localizado.

$\mathrm{Na}$ literatura disponível no SciELO que analisamos ${ }^{8}$, encontramos diversos sentidos para o que se define como do domínio psicossocial, ou simplesmente qualificado como psicossocial, a maioria sem uma definição precisa do sentido do termo. Este costuma ser usado para definir uma dimensão que não depende exclusivamente do indivíduo (quando se estuda o indivíduo) ou então qualifica fenômenos compreendidos ao mesmo tempo como "sociais" $e$ "psicológicos" querendo dizer simplesmente que não poderiam ser apenas psicológicos ou sociais. Quan-

7 Serviço de Biblioteca e Documentação, sede da BSV-Psi ULAPSI, no Instituto de Psicologia da Universidade de São Paulo.

8 Trata-se de uma revisão sobre o tema de tipo narrativa (Rother, 2007) realizada nos artigos científicos recuperados no SciELO em busca que utilizou os termos "psicossocial" ou "psicossociais" e ano de publicação (2000-2012). Indicada para os objetivos propostos neste texto, uma reflexão crítica sobre o uso do termo psicossocial no campo da saúde, escolhemos a base de dados SciELO porque esta base de dados concentra os periódicos que passam pela mais rigorosa avaliação sistemática e por incluir um número bastante expressivo e representativo dos mais bem avaliados artigos científicos brasileiros. 
do abordam o processo saúde-doença, os artigos disponíveis estão, em bom número, usando a definição de saúde da Organização Mundial de Saúde (OMS) como "bem estar físico, mental, social e espiritual".

Por exemplo, em processos de trabalho que descrevem a realização de uma anamnese ${ }^{9}$, no domínio psicossocial encontram-se as recomendações de levar em conta o contexto de vida do paciente e até mesmo uma avaliação realizada pelo profissional do local onde esta pessoa reside (sugestão comum de prática no sistema de avaliação judicial) distinta de uma abordagem baseada no clássico processo "psicodiagnóstico"10, pautado pela descrição de dinâmicas intrapsíquicas universais e sem contexto. ${ }^{11}$ Este tipo de avaliação, que incluiria a situação de vida das pessoas, tem sido denominado "avaliação psicossocial".

Muitos textos falam de "integração psicossocial" referindo-se a um trabalho de apoio ou de reabilitação para adaptação das pessoas uma nova condição de vida. $\mathrm{O}$ processo de trabalho bem sucedido no sentido da integração evita isolamento, sofrimento e a exclusão social. As expressões "adequação psicossocial" e "adaptação psicossocial" e "reabilitação psicossocial" estão associadas a essa literatura.

Quando o tema são crianças e adolescentes encontra-se uma noção de adequação associada à noção de "desenvolvimento psicossocial" utilizada no sentido da adaptação ao que se espera de cada fase da vida, fases tratadas como essenciais e universais. Consequentemente, não fazem qualquer menção ao contexto, ao gênero, à classe social e à tradição cultural nas quais crianças e jovens estão inseridos. Essa compreensão do processo de desenvolvimento está mais claramente definida quando inspirada nas diversas vertentes da psicanálise. A maioria dos artigos, entretanto, não faz referências a qualquer autor

9 Histórico que vai desde os sintomas iniciais até o momento da observação clínica, realizado com base nas lembranças do paciente.

10 Diagnósticos de doenças mentais que usam métodos ou testes psicológicos.

11 Interessante notar que se trata de uma tecnologia de avaliação psicossocial raramente ensinada nas grandes universidades. ou conceituação de desenvolvimento psicossocial. Em um grupo menor de artigos, são citados como referência documentos do Ministério da Saúde do Brasil, como os que tratam da organização de equipes multidisciplinares na comunidade (de profissionais de saúde mental, enfermagem, ginecologia e outras clínicas) para a atenção integral à saúde dos adolescentes que incluem uma noção de contexto como sinônimo de "meio ambiente".

"Entende-se por desenvolvimento psicossocial a capacidade de aquisição progressiva do ser humano de interagir com seu meio ambiente" (Ministério da Saúde, 1993, p. 37).

Como neste documento, entretanto, embora se mencione comunidade e ambiente, a maioria dos textos mantém a noção de "maturação bioposicossocial" e se refere ao "risco de anormalidade" produzida pelo contexto, maior entre os mais pobres "no campo e nas periferias dos grandes centros urbano" (Ministério da Saúde, 1993, p. 18).

Em outra direção, um conjunto crescente de textos disponíveis no SciELO considera como do domínio psicossocial o "apoio social", as "redes sociais" e as "relações institucionais" oferecido pela família, observadas no mundo do trabalho, em organizações da sociedade civil e governamentais. Quando se referem à comunidade, abordam territórios que definem uma identidade, ou a segmentos da sociedade agrupados por afinidade e identidade psicossocial, presumida ou assumida - como a de certa favela, dos homossexuais, dos grupos religiosos, ou de pessoas que vivem com HIV.

Neste conjunto de estudos, ao longo dos últimos anos somam-se os que incluem na categoria psicossocial as relações de poder e cidadania, principalmente "relações de gênero" e de classe e, mais raramente, sobre relações étnico-raciais. Referências à classe ou à pobreza, ou às "questões de gênero" (expressão que não define nada, mas sinaliza reconhecimento da desigualdade de gênero) são incluídas no domínio considerado psicossocial, inspiradas pela tradição de estudos culturais e de gênero de perspectiva construcionista. Essa tradição, ao discutir sobre a diferença encarnada em certos segmentos sociais (mulheres e homens, pobres e ricos) afirma que a de- 
sigualdade social não pode ser explicadas pela "natureza" ou por grandes processos sociais inevitáveis. São estruturantes sociais historicamente estabelecidos que socializam as pessoas, mas a desigualdade não é inevitável, nem tolerável. ${ }^{12}$ Nesse conjunto de textos, entretanto, são raros os que utilizam a classe ou o gênero como categoria de análise, na organização e narrativa do texto, como propõem Brah (2006) ou Scott $(1988 / 1995)$.

Diversos fenômenos são definidos como da ordem psicossocial nas diferentes abordagens: sentimentos, emoções, atitudes e práticas, discursos extraídos das falas de pessoas ou analisados com base em documentos, dinâmicas relacionais, resistência e resiliência, cenas e contextos. Entre os autores mais influentes que incluiria no campo construcionista, a expressão mais utilizada é "aspectos psicossociais". Expressão adotada nos estudos sobre desigualdade, quando tratam do mundo do trabalho e das organizações costumam qualificar de psicossocial a relação indivíduo-grupo/instituições, ou indivíduo-sociedade.

É visível que, mesmo sem definir mais detalhadamente o sentido prático e novas técnicas dessas concepções menos adaptativas e universalistas, se tem considerado cada vez mais o plano simbólico e cultural como algo mais expressivo da dimensão psicossocial em interação com outros "aspectos" ou "fatores" localizados na organização social e no indivíduo/sujeito/pessoa. Um número crescente de artigos define como psicossocial os "modos de ver o mundo" do sujeito/indivíduo/pessoa, assim como a produção "discursiva" e de "sentidos" nas interações sociais, interpessoais e nas instituições.

O termo sujeito é bastante utilizado, quase sempre apenas como sinônimo de indivíduo

12 Entre eles, muitos autores latino-americanos que citam Gergen e Ibañez, Berger e Luckmann ou se inspiram em George Mead e Goffman entre outros autores e os que abordam o domínio psicossocial e inspirados pelos interacionismo simbólico e pelo pragmatismo, pelos estudos culturais estudos feministas e da sexualidade. Todos leram Foucault e foram marcados pelo Marxismo e pela fenomenologia e pela hermeneutica de Gadamer, Ricouer e Habermas. ou pessoa sem definir com o uso da palavra um sentido teórico claramente definido. Nos modelos que tratam a dimensão psicossocial como expressão da associação de "fatores", o termo indivíduo é o preferido; nos indivíduos, a diversidade simbólica e cultural é reconhecida no plano das variáveis que definiriam diferentes "percepções", "crenças", "atitudes”, “opiniões", "conhecimentos", "normas" "identidades".

De interesse especial para este texto é o uso reiterado do termo psicossocial como referência ao "modo psicossocial" de organizar a assistência aos portadores de sofrimento mental, que se expressa na terminologia incluída pela SBD mencionado acima - Centro de Apoio Psicossocial. Resultado do movimento de Reforma Sanitária que concebeu o SUS, o referido uso do termo psicossocial expressa uma atenção à saúde mental organizada como assistência na comunidade (e não no hospital), além de fazer referência a uma "clínica ampliada" e aos direitos humanos, em especial às noções de "autonomia" e "dignidade" incluída no preâmbulo da Declaração dos Direitos Humanos. O modo psicossocial e a sua definição de atenção psicossocial buscam aprofundar, assim, a prática da "integralidade" no cuidado dos que padecem de sofrimento mental e das suas várias "necessidades" - também referidas como direitos; amplia o cuidado antes reduzido ao tratamento do problema definido por uma nosologia ou taxonomia. Há muitas referências no SciELO aos Centros de Atenção Psicossocial (CAPS, em alguns lugares chamados de Núcleos de Atenção Psicossocial/NAPS). Mesmo neste conjunto de textos, as práticas realizadas com base no "modo psicossocial" são pouco descritas de fato, e o termo aparece comumente para ressaltar que "nem tudo depende do indivíduo" e em oposição a um genérico "modelo biomédico".

É também interessante contrastar esses dados com o que se observa na literatura internacional. Há alguns anos, buscando os sentidos para a expressão atenção psicossocial ("psychosocial care") perguntamos à diretora científica da área de Psicologia Aplicada da APA que, reconhecendo a polissemia da expressão e a falta de definição precisa, nos ofereceu uma explicação extraída da literatura da área de serviço so- 
cial, com a intenção de apresentar "um contexto para o termo":

O termo psicossocial descreve uma constelação de necessidades sociais, emocionais e de saúde mental e o cuidado oferecido para atendê-las. Um conceito mais amplo e relacionado é o de qualidade de vida, na perspectiva da pessoa, que inclui a sua experiência em casa e não apenas o cuidado médico. O cuidado psicossocial é multifacetado porque além dos assistentes sociais outros profissionais de saúde podem contribuir para atender as necessidades psicossociais e melhorar a qualidade de vida que dependem também dos processos e ambiente geral no lar da pessoa. (S. R. Johnson, comunicação pessoal, 21 março, 2007). ${ }^{13}$

Nossa revisão crítica da literatura da década $2000-2009^{14}$, encontrou a expressão "atenção psicossocial" com o sentido de: (a) atenção aos problemas emocionais ou ao sofrimento mental que limitam o funcionamento social dos enfermos; (b) necessidade de organizar o apoio às pessoas para lidar com problemas da vida cotidiana cuja origem é social - como falta de dinheiro, de moradia adequada, de higiene e acesso aos insumos necessários para cuidar da saúde, entre outros; (c) cuidados paliativos para manter a qualidade de vida dos enfermos em fase terminal.

Bastante rara na literatura internacional e frequente na literatura brasileira, como vimos, é possível encontrar a noção de atenção psicossocial associada à (d) assistência que inclui a comunidade como parte corresponsável pela organização do cuidado dos enfermos ou portadores de alguma deficiência. Na literatura não-brasileira, os textos nessa perspectiva quase sempre discutem iniciativas realizadas ou idea-

13 Stephanie R. Johnson PhD. Diretor de Applied Psychological Science. Science Directorate American Psychological Association. Comunicação à Eliana Zucchi por e-mail, em 21 de março de 2007.

14 Pesquisa no MEDLINE e SciELO de 2000-2009, usando o termo "psychosocial care" e "atenção psicossocial" realizada com apoio de Eliana Zuchi e Bruna Robba Lara. lizadas para serem postas em prática em países em desenvolvimento ou em comunidades empobrecidas ou estigmatizadas (como dos homossexuais), especialmente em países africanos e mais afetados pela Aids, onde, na ausência de serviços de saúde organizados e tratamentos, conta-se com a comunidade para assistir aos enfermos e deficientes com cuidados paliativos.

Já no campo das medicinas, da enfermagem e da psicologia da saúde, comumente utiliza-se a categoria "fatores psicossociais" para constructos concebidos com base na análise estatística da associação de respostas a questionários. A partir de perguntas e respostas quantificáveis, as "condições de vida" e o contexto são frequentemente traduzidos como variáveis "sócio-econômicas" (escolaridade, renda, religião, cor/raça) ou "sócio-demográficas" (dados sobre os filhos e a conjugalidade). A maior parte desses estudos descreve a associação entre os fatores psicossociais (baixo conhecimento, por exemplo) como constituintes da vida de pessoas que padecem de alguma "doença" ou como efeito psicossocial, esperado, do adoecer (isolamento). O saber mediador adotado é a epidemiologia de risco. Certos grupos de indivíduos são considerados "em maior risco" depois de tipificados nessas análises, corespondem a "grupo de risco". Fatores psicossociais são associados ao adoecer e afirma-se a relevância desses fatores nos processo saúde-doença. Destes estudos, entretanto, não necessariamente os autores derivam inovação significativa para a intimidade das práticas de atenção. Quando o fazem, mais frequentemente indicam a necessidade dos pacientes mudarem de atitudes, prática que os profissionais traduzem como mais uma item de sua prática "receitadora" em técnicas que permanecem individualizante: é responsabilidade individual manter bons comportamentos e lidar com o contexto.

Os estudos sobre saúde sexual têm uma teoria mais sofisticada para interpretar a associação entre os vários fatores psicossociais. Os resultados de pesquisas clínicas ou epidemiológico-comportamentais tem sido discutidos mais diretamente à luz de teorias influenciadas pela sexologia cujos ancestrais são Freud, Reich, Kinsey e Master e Johnsons (Paiva, 2008). Também derivam práticas focalizadas nos indivíduos. 
“. . . de fato o desemprego pode causar problemas de erecção" (Abdo, Oliveira, Moreira, Abdo, \& Fittipaldi, 2005).

$\mathrm{Na}$ abordagem construcionista da sexualidade, a sexualidade é interpretada à luz das interações sociais ${ }^{15}$, das relações de poder e dos direitos humanos - direitos sexuais e reprodutivos. Raramente esses estudos deixam de derivar ações políticas e programáticas, assim como agendas de pesquisa para compreender e mitigar o sexismo, a homofobia e a inequidade de gênero, como na literatura sobre saúde da mulher e Aids. Interpretações e práticas nesta perspectiva não se pretendem generalizáveis para qualquer contexto. Foi com essa perspectiva que, ao longo da resposta à Aids, se discutiu os problemas que a noção de "grupos de risco" trouxe ao enfretamento da epidemia e à vida das pessoas afetadas - a banalização desta noção estimulou o estigma e a discriminação de segmentos identificados como de risco, além de incitar a negação do problema em pessoas que não se identificam com esse estigma, sem oferecer propriamente técnicas e práticas ou processos de trabalho apropriados e segundo os princípios do SUS (Ayres, Calazans, Saletti, \& França, 2006).

A noção de risco psicossocial, entretanto, ainda predomina no campo da psicologia da saúde, hospitalar e nas abordagens mediadas pela epidemiologia. Predomina mesmo quando se substitui o termo "risco" por "vulnerabilidade" sem que o sentido se altere, como discutimos a seguir.

15 John Gagnon, é o cientista social que incluímos como ancestral do construcionismo e de uma abordagem dramatúrgica do psicossocial, que muitos autores adotam nesse suplemento. Interacionista e herdeiro do pragmatismo e da Escola de Chicago, seu uso da "carreira" e "trajetória" ajudou-o a definir, com Simon (Simon \& Gagnon, 1969) e antes de Foucault, o sexo como uma atividade social como outra qualquer e como os discursos sociais sobre o sexo substituem com vantagem a noção de impulso. A conduta sexual, em termos simbólicos e físicos, pode expressar outros interesses (trabalho, política, religião) que não tem prioridade na explicação causal. Ou seja, inverte Freud ao afirmar que o sexo pode significar quase tudo na vida social e o sexual não tinha prioridade na explicação causal (Gagnon, 2006, p. 406).

\section{A Dimensão Psicossocial na Organização das Práticas de Saúde}

No campo da organização das práticas de saúde e de modo similar, como veremos nessa seção, palavras compostas sintetizam o debate sobre como conceber o processo de produção da saúde e da doença que produziu três movimentos paradigmáticos ao longo da segunda metade do século XX. Palavras compostas também expressam uma direção de ações imprecisamente descritas. A sua definição como biopsicosocial, como vimos no caso da saúde do adolescente, pretende a ampliação da perspectiva exclusivamente biológica ou biomédica e exige uma atuação multiprofissional.

Como discutido em Ayres, Paiva e França (2010/2012), o quadro conceitual que, nos anos 1950 , primeiro postulou a superação dos limites disciplinares entre a intervenção social em saúde pública e a clínica, entre tratamento e prevenção é conhecido como o modelo da História Natural das Doenças (HDN). Leavell e Clark (1958) descreveram períodos de uma "história natural da doença" (HND) que exigiriam uma construção interdisciplinar para intervir sobre a multicausalidade das doenças considerando os três níveis de prevenção (NP). Para este modelo conhecido como o HND-NP, ações de prevenção primária evitam a instalação da doença no período definido como pré-patogênico (por exemplo, com a aplicação de vacinas, o uso de preservativo); no período patogênico, quando o agravo se instalou, a prevenção secundária (a partir da detecção precoce e a intervenção clínica adequada) evita o avançar da doença e sua transmissão, favorecendo melhores desfechos individuais e coletivos; a prevenção terciária (por meio da reabilitação e do tratamento continuado) resgataria a melhor qualidade de vida possível em situações de sequela ou cronificação inevitáveis. Neste modelo, a epidemiologia do risco surgiu como um dos principais saberes articuladores deste esforço interdisciplinar.

O segundo movimento fundou a "Nova Promoção da Saúde" (NPS), depois de seguidas conferências internacionais ao longo dos anos 1970 que fortaleceram a centralidade das práticas de prevenção e atenção primária, ques- 
tionando a centralidade do hospital como foco da ação política e programática em saúde. Os determinantes sociais da saúde e as ciências sociais ganharam relevância nesse movimento, que concebeu a melhoria das condições de saúde individual e coletiva com base em princípios orientadores que validaram no Brasil a inclusão do direito universal à saúde na Constituição de 1988. A NPS ao mesmo tempo afirmava uma concepção integral de saúde (física, mental, social e espiritual), a ação intersetorial, o envolvimento na transformação de situações sociais e em ações multiestratégicas que promovessem a equidade e a sustentabilidade das ações em saúde, e a participação de usuários. ${ }^{16}$ Todos são princípios orientadores do Sistema Único de Saúde brasileiro que a organização da resposta brasileira à Aids buscou implementar.

Introduziram-se, desde a NPS, algumas práticas para manejo de "variáveis" sociais. A psicologia que faz parte deste movimento também identificou aspectos psicossociais da cadeia multicausal responsável pelo adoecimento. Muitas práticas em psicologia na saúde constituíram-se no Brasil neste esforço pela integralidade, e os psicólogos que conversaram com a clínica médica e interagiram no âmbito das práticas genericamente definidas como de "perspectiva biopsicossocial" produziram novos arranjos de técnicas e procedimentos. F. M. Santos e Vilela (2009) definem esses arranjos como "coletivos de pensamento" e nomeiam os mais estruturados e atuantes em hospitais gerais: a Psicologia da Saúde, a Psicologia Médica, a Psicologia Hospitalar e Saúde Mental que, na atenção em saúde, tem como fundamento principalmente a psicossomática, o referencial teórico psicanalítico e a psicologia existencial.

Muitos autores dessas tradições teorizaram o viver com Aids ou interpretaram a associação entre estilos de vida e a prevenção do adoecimento e da infecção pelo HIV segundo modelos sociopsicológicos (sociopsychological) aplicados à saúde. ${ }^{17}$ No caso da resposta à Aids, por-

16 Então como resultado da Reforma Sanitária.

17 Neste último caso, Bandura, Proshaska, Lazarus e Folkman, entre outros, são os autores mais co- tanto, essas psicologias estruturavam a prática em "saúde mental" dos serviços especializados para pessoas vivendo com HIV. Como discuti em Paiva (2012b), antes da produção da medicação antiHIV, a literatura internacional sobre as práticas junto aos doentes reduzia-se aos estudos sobre stress e coping, que investigavam as associações estatisticamente significativas entre experiências de vida cotidiana e adoecimento ou modos de lidar com este. Mais adiante e especialmente pra pensar a prevenção, a literatura sociopsicológica introduziu análises com base em variáveis sociais (cor da pele, escolaridade, local de moradia, sexo, identidade sexual e religiosa, principalmente. Dois saberes têm mediado essas práticas sociopsicológicas no quadro da NPS: a tradição epidemiológica e as abordagens da psicologia comportamental e sociocognitiva.

Outras abordagens psicossociais dedicadas a instrumentalizar o acolhimento e cuidado para além da chamada "saúde mental" tiveram mais dificuldades de se estabelecer como referência para a prática. Alternativas desenvolveram-se mais facilmente no campo da prevenção e da atenção básica em saúde, onde as práticas estavam menos consolidadas pelos coletivos tradicionais de psicólogos e havia maior estímulo à interdisciplinaridade. No caso da Aids, outros profissionais (enfermeiros, assistentes sociais, nutricionistas, educadores, além de médicos e paramédicos) sempre atuaram enfocando aspectos psicossociais do aconselhamento pós-teste, da adesão ao uso do preservativo e da medicação, e em diversas atividades psicoeducativas desenvolvidas na atenção básica e nos serviços especializados.

A alternativa de uma referência mais definida para instrumentalizar a prática surgiu mais forte quando um terceiro paradigma para pensar o processo saúde-doença foi desenvolvido: o quadro da vulnerabilidade e dos direitos humanos (V\&DH), sistematizado e validado internacionalmente justamente ao longo da construção da resposta à Aids nos anos 1990 (Gruskin

nhecidos (Tunala, 2012), que permanece como a mais citada na literatura internacional da chamada "psicologia da saúde". 
\& Tarantola, 2012; Mann \& Tarantola, 1996; Mann, Tarantola, \& Netter, 1992). O quadro da V\&DH ampliou significativamente as perspectivas biopsicossocial e sociopsicológicas que cresceram com a Nova Promoção da Saúde na direção de incorporar determinantes sociais da saúde para, então, pensar a vulnerabilidade individual e social ao adoecimento como inextricavelmente integradas a uma dimensão programática, como a Figura 1 pretende ilustrar - dimensão que se realiza na abordagem baseada em direitos humanos (Gruskin \& Tarantola, 2012; Mann, Gruskin, Grodin, \& Annas, 1999).

No Brasil, a perspectiva dos direitos humanos foi bastante expandida: os planos individual, social e programático têm sido concebidos como planos de intersubjetividade, como da esfera da dinâmica da vida cotidiana, da cidadania e do sujeito portador de direitos (Ayres, Paiva, \& França, 2010/2012; Paiva, 2012a). Este quadro produziu uma das vertentes de abordagem psicossocial construcionista na saúde e substituiu a noção de indivíduo concebido como conjunto de fatores biosociopsicológicos, da original obra de Mann e colaboradores, pela concepção de pessoa em contexto, sujeito da saúde e do direito à saúde (Paiva, 1996, 2002, 2008, 2012a, 2012b). Reconhecendo o avanço que a introdução das variáveis sociais na psicologia da saúde significou no necessário diálogo interdisciplinar, a unidade central ou porta de entrada da abordagem da dimensão psicossocial não é um "indivíduo", considerado como uma entidade que a tradição da social-psychology concebe como constructo resultante de fatores sócio-cognitivo-comportamentais. A unidade de análise escolhida é a cena da interação intersubjetiva (nos serviços, na vida social e cotidiana, em uma trajetória pessoal). Todos os 3 planos da vulnerabilidade estão mutuamente implicadas como a Figura 1 indica.

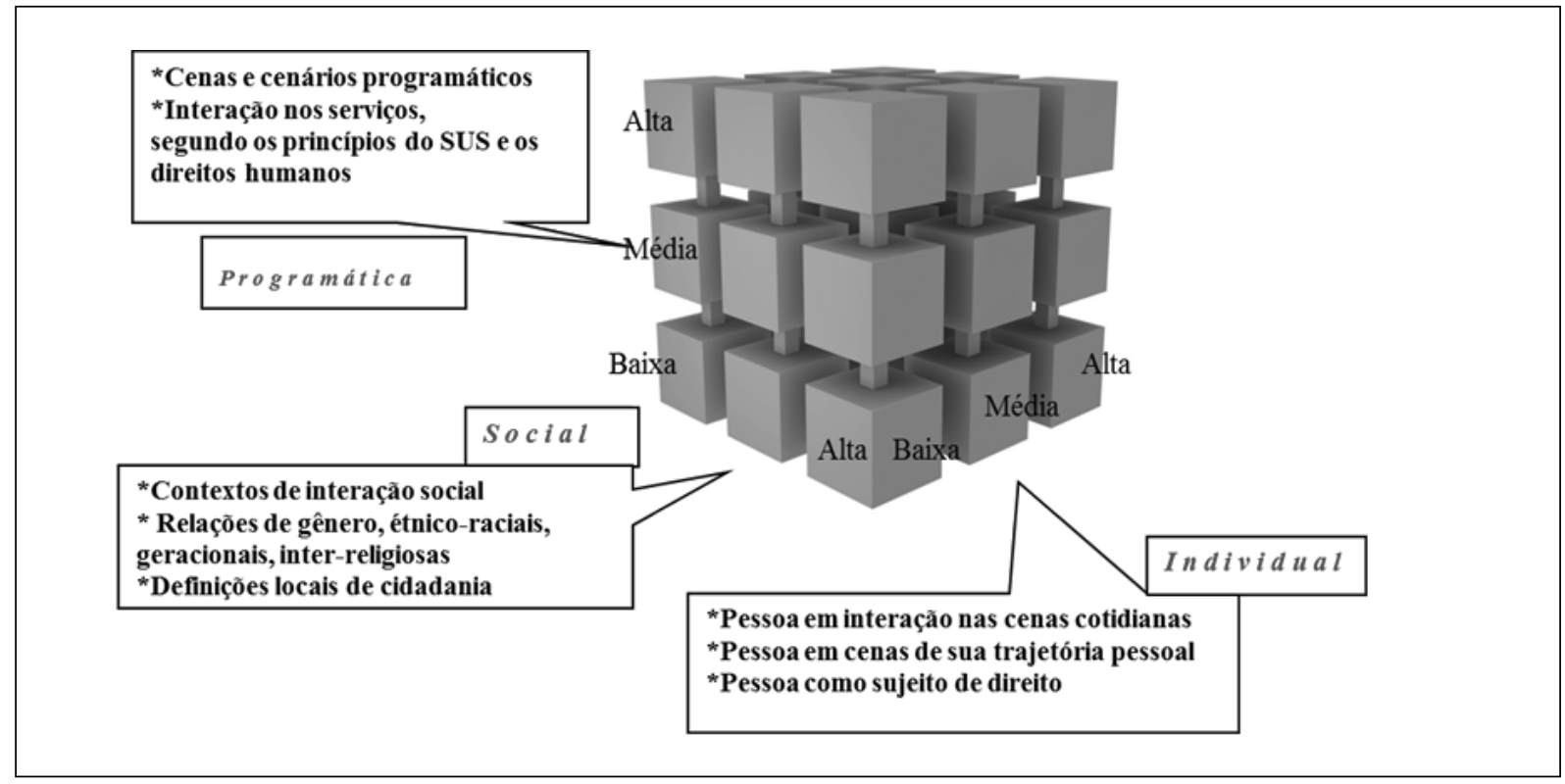

Figura 1 - Interdependências das dimensões social, programática e individual da vulnerabilidade concebidas como intersubjetividade.

Uma primeira novidade a ressaltar deste terceiro movimento (V\&DH), em contraste com a NPS, é o peso expandido que se dá ao político-programático, um determinante social e intersubjetivo que é mediador da vulnerabilidade social e individual. Sinteticamente, a vulnerabilidade ao adoecimento de pessoas que pertencem a segmentos socialmente mais vulneráveis e marginalizados (por exemplo, os mais pobres) diminui ou aumenta na presença ou ausência de programas de saúde (por exemplo, a aplicação de vacinação, a existência de saneamento básico, ações de prevenção da Aids, acesso à atenção médica e a tratamentos). Essa abordagem explica alguns dos sucessos do Brasil na diminuição da propagação da Aids ainda nos anos 1990, antes de se reduzir a pobreza, o machismo, a homofobia e o estigma associado à doença, ou resolver 
os problemas do abuso de drogas e do acesso universal à saúde integral. Os programas de Aids desenvolveram iniciativas inovadoras que abordaram tecnicamente e programaticamente esses determinantes, e obtiveram resultados surpreendentes.

Essa mediação programática expressa de modo emblemático que quanto maior o desrespeito aos direitos humanos, maior a chance de adoecimento; de modo contrário, quanto maior o esforço de promoção e proteção de direitos - à saúde integral, dos direitos sexuais e reprodutivos, a não discriminação, à segurança alimentar, à moradia digna, ao emprego decente, entre outros - maior a sobrevida e a chance de não se infectar. Assume-se nesse quadro, como princípio, que cada sociedade deve proteger e promover direitos para promover saúde e que seus governos (nacionais e locais) podem ser responsabilizados em caso de displicência ou violação (Gruskin \& Tarantola, 2012). O uso deste princípio, por ativistas e profissionais de saúde no SUS e em condições de responder às demandas do movimento social, foi marcante na produção da resposta brasileira à Aids

Trata-se de superar a individualização, assim como a culpabilização da "vítima" ou responsabilização apenas da pessoa pelo "mau comportamento" e pelos fatores contextuais associados ao seu adoecimento. Programas e práticas baseados em uma análise da vulnerabilidade ao adoecimento necessariamente dependem da ação de diversos saberes em interação (de diversas clínicas, da epidemiologia, das ciências humanas e sociais) e de práticas na perspectiva dos direitos humanos (da gestão ao cuidado), ou seja, que o sistema não discrimine, que garanta acesso universal aos serviços de saúde, a sua aceitabilidade e qualidade, e a participação dos usuários.

Para pensar a chamada dimensão individual da vulnerabilidade, portanto, abandonamos no Brasil rapidamente a social psychology que ilustrava a obra original de Mann et al. $(1992,1997)$. Ativa na literatura norte-americana e europeia, como era de se esperar ${ }^{18}$, esta perspectiva sócio

18 Nossa produção autoctone na América Latina tem pouca força de disseminação, especialmente por- psicológica permaneceu hegemonicamente disseminada pelas instituições das Nações Unidas que adotaram o quadro da $\mathrm{V} \& \mathrm{DH}$. A tradição latino-americana da pedagogia, da psicoterapia e do teatro do oprimido (Boal, 1975; Freire, 1968/1973; Moffat, 1987; Oliveira \& Araujo, 2012), em outra direção, inspirou uma psicologia dedicada à ação social e comunitária, que alguns chamam de "intervenção psicossocial", sintomaticamente definida como unitermo pela SBD e não pela APA, como discutimos acima. Implicada na construção da cidadania pós-colonial e pós-ditaduras, essa mesma tradição produziu "o modo de atenção psicossocial" introduzido no Sistema Único de Saúde brasileiro.

Este foi o contexto para o surgimento do movimento teórico-prático que se dedica a elaborar uma abordagem psicossocial na saúde no quadro da V\&DH (Paiva, 2012b). Constrói-se neste quadro, como em outras vertentes construcionistas, uma alternativa à noção de indivíduos "alvos" da intervenção, modelagem, da receitação e da educação bancária ou da pregação moralizante (Paiva, 1996, 2002, 2007). Preferimos o termo pessoa, utilizada na linguagem dos direitos, e as definições de sujeito das diferentes vertentes construcionistas (Cañón, 2008).

Nesta abordagem psicossocial no quadro dos Direitos Humanos e da Vulnerabilidade ${ }^{19}$, o sujeito é concebido (a) como sujeito dos discursos a que cada pessoa tem acesso em sua trajetória e processo de socialização, processo que não a sujeita (e domina) fundamentalmente; as pessoas, como a antropologia e a psicologia social na saúde indicam há décadas, vivem a reinterpretar discursos em diversos contextos de sua vida. Em seu cotidiano, por exemplo, as pessoas são "sujeitos sexuais" ao reelaborar os diversos

que não escrevemos (e, portanto, pensamos) em inglês.

19 Quando estamos compreendendo e interpretando os dados de vários saberes sobre a vulnerabilidade de uma pessoa ou de um segmento social a um agravo de saúde costumo dizer que estamos no quadro da V\&DH. Quando estamos desenhando e planejando a prática, os princípios das abordagens em direitos humanos ganham destaque e costumo inverter a sigla DH\&V. 
discursos sobre o sexo (o da prevenção, o da religião, o da mídia) para realizar suas sexualidades a cada ocasião e cena (Paiva, 1996, 2007) Como "sujeitos religiosos", interpretam dogmas e o discurso religioso adaptando-os à sua religiosidade pessoal (García, Muñoz-Laboy, Almeida, \& Parker, 2009; Silva, Santos, Licciardi, $\&$ Paiva, 2008). Como (b) sujeito de direitos e em solidariedade com outras pessoas, pode-se decidir pela ampliação e especificação de novos direitos. É como sujeito de direitos que o usuário do serviço deve ser concebido na intimidade das práticas e técnicas dessa abordagem psicossocial: como sujeitos nos encontros de cuidado, sujeitos da aprendizagem em solidariedade com outros, como agentes da sua emancipação da opressão psicossocial e da vulnerabilidade ao adoecer (Paiva, 2002, 2008, 2012a; Seffner, Paiva, \& Pupo, 2012).

A produção latino-americana dessa vertente de psicologia social na saúde está, portanto, na mesma direção da reflexão crítica expressa por Frosh (2013) que também discute o limite das teorias chamadas de sócio-psicológicas (socio-psychological) e individualizantes. Frosh ressalta que esta sócio psicologia investiga cognições e comportamentos em contextos sociais operando a noção de indivíduo como um dado, não como um constructo, sustentando a divisão intelectual de trabalho que separa em disciplinas diferentes os que estudam a sociedade (o social antes do hífen) dos que estudam o indivíduo (o psicológico depois do hífen). Frosh, entre muitos, valoriza a intersecção. Desafio complementar, na sua perspectiva, seria superar a noção de que existe algo "objetivo", o indivíduo, que pode ser estudado de uma posição "neutra", sem responder ao contexto e as ideias que o habitam. O autor valoriza as noções do "asujeitamento" ao trabalho da sociedade, na formulação de Butler (1997), e a possibilidade de sermos "sujeito" com poder de agir no mundo. Trata-se de uma ampliação da inspiração europeia assentada em Freud e Marx que conceberá e pesquisará um sujeito que é, ao mesmo tempo, social e psicológico para além da repressão, constituído socialmente, portador de agência e de vida interior.

No Brasil, desde os anos 1990, essa mesma crítica informava a produção das diversas vertentes da psicologia social construcionista, inclusive na saúde (Spink, 2013). Não por acaso, essa vertente aglutinou muitos autores implicados na resposta à Aids em algum momento de sua trajetória profissional. ${ }^{20}$ Todos reconhecemos a centralidade do campo dos estudos de gênero e da sexualidade, que ampliou sua legitimação justamente no âmbito da resposta à Aids e às demandas da organização da saúde integral da mulher.

Posicionando nossa crítica construcionista no campo dos direitos humanos e da vulnerabilidade, nos parece significativo que sócio venha antes de psicológico nos modelos de intervenção e práticas resultantes de estudos da psicologia da saúde ou da epidemiologia sociopsicológica. Como mediação para delinear a prática, estes modelos se baseiam nas associações entre fatores obtidas em grandes amostras, com base em dados agregados e populacionais que fazem sentido apenas para estudos de tendências e probabilidades macrossociais. Quando não recorrem a outros saberes (clinico, educacional) colonizam indevidamente, portanto, as práticas de cuidado e de prevenção como se essas tendências populacionais fossem encontradas desta mesma maneira, com essa mesma dinâmica, na vida cotidiana das pessoas. Ao fazer isso, não conseguem oferecer recursos técnicos para renovar a intimidade das práticas.

20 O Brasil organiza há 18 anos o maior encontro que debate exclusivamente gênero ("Fazendo Gênero") que junta milhares de pesquisadores brasileiros, literalmente. A América Latina é co-produtora da grande virada epistemológica produzida pelos estudos de gênero e sexualidade construcionista, inspiração fundamental dessa vertente da psicologia há mais de duas décadas. Como Terezita de Barbieri sintetizou, a produção da categoria gênero de análise é "uma ruptura epistemológica, talvez a mais importante nas ciências sociais nos últimos 20 anos, porque reconhece uma dimensão da desigualdade social até então não tratada, subsumida na dimensão econômica, nas teorias de classe e de estratificação social" (Barbieri, 1991). Os autores do campo da Aids valorizam os estudos de gênero bem antes de a obra de Butler ser conhecida e conquistar finalmente os que, de algum modo, foram inspirados, como ela, pela tradição psicanalítica. 
Como saber mediador único, a análise de risco coloniza indevidamente outros campos de saber, como o do cuidado das pessoas e da prevenção, com receitas de "estilos de vida adequados" para indivíduos "genéricos", biopsíquicos/comportamentais, pessoas-tipo, que existem apenas em questionários. Um exemplo dessa colonização ineficaz é a insistência na pregação universal do preservativo que, mais de 20 anos depois, tem mostrado seus limites. O movimento social de Aids no Brasil insiste, desde 2011, que na $4^{a}$ década da epidemia teríamos necessidade de singularizar a prevenção, pensar nas relações de gênero (mulheres não usam o preservativo disponível e dependem de técnicas de conversa) e que cada pessoa tem o direito de utilizar todos os recursos de prevenção disponíveis no contexto suas interações sexuais, inclusive os biomédicos (ver http://oquenostiraosono.tumblr.com/ home).

Como recentemente sintetizaram Kippax, Stephenson, Parker e Aggleton (2013), as concepções sobre o plano do indivíduo adotado nas abordagens da epidemiologia de risco e sócio psicológicas e por certa versão do quadro da V\&DH adotada pela Organização Mundial da Saúde ${ }^{21}$, esquecem: (a) que as ações das pessoas não são simples produtos de suas características ou de suas escolhas racionais e estão implicadas em sentidos e significados; (b) que, portanto, quando o plano do indivíduo é reduzido a um determinado comportamento (o ato sexual sem o uso do preservativo) fazem desaparecer os diferentes significados que práticas assumem ao longo do tempo para uma mesma pessoa, para os diferentes lugares que ocupa e ocasiões que vive (como cônjuge ou amante; por amor ou sendo abusado); (c) que a normatividade cultural e as práticas sociais produzem constantemente o indivíduo e suas práticas.

Kippax e colegas (2013) substituem a noção de indivíduo como foco da prevenção pela centralidade da comunidade, ou seja, pela focalização na ação coletiva e interação entre grupos e redes de pessoas. Mudanças sociais e de comportamento que foram articuladas comuni-

21 Expresso em documento da UNAIDS (Joint United Nations Program on HIV/AIDS, 2011). tariamente transformaram os rumos da epidemia da Aids, argumentam. Como exemplos da centralidade dessa noção de movimento comunitário para a promoção da saúde lembram que a introdução do uso do preservativo, um artefato contraceptivo, passou a ser norma entre homens gays que, nos anos 1980, se organizaram em um movimento social de resistência à epidemia; argumentam que as mobilização da solidariedade e do cuidado comunitário produziram o acesso universal ao tratamento antirretroviral na resposta brasileira à Aids, discutida em vários artigos deste suplemento.

Por outro lado, o desafio apontado por Frosh, por Kippax e outros construcionistas parece quase insuperável para quem trabalha no campo da saúde, onde a ambição de objetividade e o manejo cirúrgico e clínico do corpo individual, indivíduo extraído de seu contexto cultural, têm efeito prático inquestionável. Considere o tratamento da infecção pelo HIV de uma pessoa vivendo com Aids, por exemplo: seus protocolos resumem um conjunto de hipóteses teóricas testadas com técnicas e práticas que se apoiam em rigoroso manejo de substâncias, produtos, em corpos extraídos de seu contexto social para serem medicados e tratados, em qualquer outro continente com eficácia inquestionável! Os antirretrovirais controlam a infecção pelo HIV em qualquer parte do planeta! Os espaços de prática multidisciplinar, alternativamente, dependem da superação desta noção de indivíduo biológico-comportamental para que se adotem abordagens tecnocientíficas que reconheçam que remédios são eficazes quando se garante o acesso a eles e adesão ao tratamento, tarefas implicadas no contexto sociocultural, como esse suplemento discutirá.

Essa mesma discussão realizada no campo da sexualidade também parecia insuperável no início da epidemia da Aids, quando a literatura global e as psicologias exportadas para várias outras formações disciplinares (em educação e na saúde) expressavam a hegemonia da tradição sexológica que concebe um sexo biopsicológico, com igual dinâmica e desenvolvimento psicossexual universal. Essa abordagem ainda se dedica a revelar as verdades sobre o sexo essencial e a descobrir o psicossexual normal obtido por meio 
de inquéritos clínicos ou surveys populacionais que definem o "normal" e derivam práticas diretamente para a clínica de transtornos sexuais. Para que a prevenção da transmissão sexual do HIV começasse a ter alguma eficácia, a resposta à Aids também precisou apontar os limites desta concepção sobre o sexo e das suas técnicas dedicadas a garantir o "desenvolvimento psicossexual normal" ou "saudável", como nos programas para adolescentes (Paiva, 2008, 2012b; Paiva, Ayres, \& França, 2004).

O reconhecimento dos limites destes essencialismos para responder à Aids permitiu o crescimento de visões alternativas. Especialmente no hemisfério sul ou nos bolsões do hemisfério norte onde ficava evidente que uma sinergia de pragas (Parker \& de Camargo, 2000) que produz a desigualdade social assentada na dominação de classe, nos sexismos, no racismo e na naturalização de genocídios de africanos e homossexuais que sustentava a explosão dos casos de Aids. A epidemia descontrolada exigiu que a reflexão crítica chegasse mais rapidamente à reformulação de protocolos para a prática que, então, se desenvolveram implicados na referência ético-política dos direitos humanos; e permitiu que se renovasse a técnica (saber operacional que tem caráter normativo, prescritivo e metodológico) e a teoria (o saber teórico de caráter analítico e compreensivo).

Em outras palavras, onde há sinergia de desigualdades, estigmatização e maior vulnerabilidade ao adoecimento, um hífen é pouco! Os envolvidos em promover a saúde precisavam das flechas da interação e integração, de sinergia de saberes e intervenções em diferentes dimensões institucionais, estruturais e políticas. A emergência da epidemia da Aids, em todo lugar, acirrou a necessidade de agir sincronicamente, dinamicamente e ao mesmo tempo, sobre todas as dimensões que afetam o processo saúde-doença. Nessa direção, tem sido fundamental manter aceso um diálogo interdisciplinar enquanto se estruturam espaços integrados para ação, e para reconstruir práticas resultantes deste diálogo que beneficiassem segmentos tradicionalmente incluídos na vida social pela via da discriminação (Ayres, Paiva, \& Buchalla, 2012).
Portanto, uma segunda novidade do quadro da $V \& D H$, que também distingue sua abordagem psicossocial das outras vertentes construcionistas na psicologia social, é sua a ambição de produzir encontros férteis entre diversos saberes. $O$ crescimento do enfoque hermenêutico incluído na versão brasileira do quadro da V\&DH o diferencia. A hermenêutica no sentido filosófico da obra de Gadamer (1997), e não apenas no sentido metodológico, introduziu uma perspectiva da relação eu-outro nos seus aspectos não apenas cognitivos, mas éticos, morais, políticos e estéticos (Ayres, 2007, 2008). Seja para abordar a vulnerabilidade começando pela dimensão individual ou social, seja desde o plano programático, a hermenêutica interdita o objetivismo que promove a redução do social aos estilos de vida, as dicotomias entre o individual e o coletivo, entre o biológico e o social; interdita também o sentido puramente instrumental dos aspectos estruturais e a politização que permanece externa aos aspectos tecnocientíficos. Os aspectos sócio-estruturais devem estar implicados na prática (definido como saber baseado nas relações interpessoais, intersubjetivas que é responsivo e particularizado). Esta hermenêutica permite politizar a teoria e a técnica na intimidade de seus protocolos. ${ }^{22}$

Esta hermenêutica produziu a noção de Cuidado no quadro da vulnerabilidade (Ayres, 2004a, 2004b) e valoriza a centralidade do cuidado adotada em vários campos de saberes e práticas em saúde (Pinheiro \& Lopes, 2010; Pinheiro \& Mattos, 2006). Motivada por diferentes vias e experiências, a aproximação do movimento V\&DH desta perspectiva filosófica por vários autores brasileiros em campos como medicina, nutrição, saúde da mulher e enfermagem, permitiu uma produção teórico-técnica sobre o psicossocial que deveria chamar a atenção para a importância e relevância de referida perspectiva.

O objetivismo, as dicotomias e o estrutural concebido como barreira, assim como a política tratada como fator externo ainda persistiram,

22 Sobre essas definições de teoria, técnica e prática ver Pupo (2012). 
mesmo que de contrabando, nos discursos e propostas da NPS e nas versões da vulnerabilidade criticadas por Kippax e colegas (2013). No Brasil, a pedagogia de Paulo Freire já superava essa externalidade no campo da educação com sua pedagogia anticolonização que também inspirou concepções de promoção da saúde em todo mundo. A inclusão da hermenêutica no Brasil fortaleceu a opção pelo uso multicultural e emancipatório das abordagens em Direitos Humanos, como propõem Boaventura Souza Santos (2003), cuja hermenêutica diatópica opera o quadro dos direitos com uma preocupação anticolonialista, como a de Freire (Paiva, 2012a).

Essa segunda novidade, a perspectiva hermenêutica, ressalta a centralidade da intersubjetividade para pensar a saúde no plano individual, social e programático (como se sintetiza na Figura 1) e destaca a reflexão crítica ao individualismo. Porque o sentido forte de diálogo na perspectiva hermenêutica, como para Gadamer, é o da "fusão de horizontes" (Ayres, 2007), a reflexão crítica se dará também com participação direta de usuários dos serviços, nos encontros de cuidado e em qualquer plano institucional e político. Abordagens psicossociais estão implicadas na produção de práticas de atenção, prevenção e educação, assim como no planejamento e na gestão em saúde. Recupera-se das intervenções estruturais sua dimensão intersubjetiva: melhor que denunciar os traços macrossociais da desigualdade será compreender a concretude das relações de gênero e raciais, de classe e de geração na vida cotidiana, no modo como é experimentada em cada território e por cada pessoa, que também encontramos nas práticas em saúde e no modo como se realizam.

Finalmente, a perspectiva psicossocial adotada nesta vertente brasileira da $\mathrm{V} \& \mathrm{DH}$ não prescinde da centralidade da pessoa, concebida como sujeitos em interação com outros e como sujeito em relação com os direitos humanos. Como sujeito em relação toda pessoa pode experimentar um dado processo de adoecimento ou se proteger dele, o que envolve sua constituição física e o modo singular de produzir seu cotidiano, como parte de uma comunidade. Como sujeito portador de direitos pode reivindicá-los ou, como agente comunitário ou do estado, solidariamente promover e proteger os direitos de outras pessoas que deve encontrar como co-cidadãos. Comunidades não existem apenas abstratamente nas normas e referências culturais. Além de estarem encarnadas em pessoas que irão reproduzir a história de cada comunidade em seu cotidiano, dependem de pessoas que serão agentes institucionais para legitimá-las em suas práticas e ao longo da socialização de novas gerações. $\mathrm{Ou}$, muito pelo contrário, das pessoas que serão agentes a inspirar e organizar transformação da comunidade liderando movimentos sociais. ${ }^{23}$

Esta perspectiva e abordagem na saúde neste quadro dos direitos humanos e da vulnerabilidade são, portanto, psicossociais e não sociopsicológicas (socio-pyschological).

Nesse modo de interpretá-la, a vulnerabilidade ao adoecimento será sempre de uma pessoa (uma mulher) - não de um grupo de risco (prostitutas) ou de uma comunidade (um território, um grupo solidário que compartilha uma identidade) - em uma determinada situação social (vivida como cenas dinâmicas com um cenário sociocultural pela pessoa) onde seus direitos estão garantidos - ou violados, negligenciados. A vulnerabilidade a um agravo de saúde será maior ou menor na presença ou ausência de um programa (de prevenção, de apoio, de assistência à sua saúde). A maioria das mulheres brasileiras vivendo com HIV - que tiveram, em média, apenas um ou dois parceiros na vida ou uma proporção das prostitutas negligenciadas em seus diretos básicos e sem acesso a programas de prevenção - exemplificam a fertilidade desta perspectiva.

23 A noção de "encarnada" está na mesma direção da noção de "embodied health movements" que discute movimentos de saúde nos Estados Unidos (Brown et al., 2004). Os autores discutem que esses movimentos introduzem o corpo biológico em movimentos sociais em narrativas de sua experiência de sofrimento e negligência, especialmente, sua experiência emocional e não apenas cognitiva; interpelam a medicina e ciências hegemônicas; incluem a colabração de ativistas com cientistas e profissionais de saúde para acessar tratamentos, prevenção, pesquisa e financiamentos. 


\section{O Processo de Renovação das Práticas deve Ousar Até a Renovação da Teoria}

A contribuição das ciências sociais, da história e da filosofia tem sido central para o desenho de novas práticas e para a inovação teórica produzidas no bojo da resposta à Aids brasileira. No caso da psicologia, ao produzir uma vertente mais politizada ${ }^{24}$ da psicologia social na saúde, pode-se informar as práticas das psicologias que, desde o saber clínico, focalizam o intersubjetivo e produzem coletivos multiprofissionais dedicados à saúde individual e coletiva no âmbito do SUS. Foi longo o caminho para validação de sua eficácia prática, intensas as mudanças de rotas para que essas práticas e seus saberes específicos, e seus princípios, fossem aplicados com sabedoria nas ações do cotidiano de trabalho de cuidado das pessoas vivendo com Aids ou das populações mais vulneráveis socialmente. $\mathrm{O}$ que o quadro da vulnerabilidade nos ensinou é que não há uma História Natural da Doença, senão uma história social da doença, não só porque são sociais e históricos os conteúdos dessa História, mas porque social e histórica é também a forma de contá-la (Ayres, Paiva, \& França, 2010/2012), como alguns artigos deste suplemento ilustrarão.

No caso da Aids, essa resposta brasileira precisava ser articulada às práticas em saúde de um sistema universal e que apenas começava a ser construído quando a epidemia explodiu. $\mathrm{Pa}$ ralelo ao surgimento da epidemia, para dar conta do compromisso de universalidade, equidade e integralidade, o Programa de Assistência Integral à Saúde da Mulher (PAISM) já inovava, superando o hífen "materno-infantil" com outros termos: "mulher" e "integral". A perspectiva feminista e marxista-construcionista acumulada nas ciências sociais, na educação e no campo da saúde sexual e reprodutiva que hoje mar-

24 Farr (1998) fala de uma psicologia social sociológica (em contraste com a psicologia social psicológica). Aqui estamos pensando em politizada no sentido de pensar poderes, desigualdade e a intimidade das políticas públicas. cam o movimento de humanização das práticas de saúde brasileiro, remonta à década de 1980 . Somou-se a esse movimento, como inspiração da resposta à Aids, a produção latino-americana de psicologia social comunitária, do oprimido e de intervenção psicossocial, que dialogava com a antipsiquiatria, institucionalizada no Brasil como Reforma Psiquiátrica e Luta Antimanicomial que produziu o "modo psicossocial" na saúde mental.

Apenas recentemente esse esforço de reflexão crítica e sistematização das práticas exigidas pela organização do SUS e, mais recentemente, de um Sistema Único de Assistência Social (SUAS) começa resultar em textos escritos que traduzem uma importante renovação teórica. Essa produção é especialmente visível na segunda década do século XXI.

É preciso ter coragem de transformar coletivos de pensamentos e práticas em aportes teóricos que sustentem a formação disciplinar dos psicólogos brasileiros das próximas gerações, ainda presos a escolas dogmáticas, a este ou àquele autor de outro século, ou às socio psicologias produzidas em outro contexto social. Esperamos que esse suplemento ajude a estimular outros números especiais da revista, de diferentes campos e temas, mas com esse mesmo espírito de inovação teórica e técnica e prática!

\section{Referências}

Abdo, C. H., Oliveira, W. M. de, Jr., Moreira, E., Jr., Abdo, J. A., \& Fittipaldi, J. A. S. (2005). The impact of psychosocial factors on the risk of erectile dysfunction and inhibition of sexual desire in a sample of the Brazilian population. São Paulo Medical Journal, 123(1). Recuperado em 17 jun., 2009, de http://www.scielo. br/scielo.php?script=sci_arttext\&pid $=$ S1516$-31802005000100003 \& \operatorname{lng}=\mathrm{en} \& \mathrm{nrm}=$ iso

Ayres, J. R. (2004a). Cuidado e reconstrução das práticas de saúde. Interface: Comunicação, Saúde e Educação, 8(14), 73-92.

Ayres, J. R. (2004b). O cuidado, os modos de ser (do) humano e as práticas de saúde. Saúde e Sociedade, 13(3), 16-29.

Ayres, J. R. (2007). Uma concepção hermenêutica de saúde. Physis, 17, 43-62. 
Ayres, J. R. (2008). Para comprender el sentido práctico de las acciones de salud: contribuciones de la herméutica filosófica. Salud Colectiva, 4, 159-172.

Ayres, J. R., Calazans, G., Saletti, H., Filho, \& França, I., Jr. (2006). Risco, vulnerabilidade e práticas de prevenção e promoção de saúde. In G. W. S. Campos, M. C. S. Minayo, M. Akerman, M. Drumond Jr., \& Y. M. Carvalho (Orgs.), Tratado de Saúde Coletiva (pp. 375-417). São Paulo, SP: Hucitec.

Ayres, J. R., Paiva, V., \& Buchalla, C. M. (2012). Direitos Humanos e Vulnerabilidade na Prevenção e Promoção da Saúde: Uma introdução. In V. Paiva, J. R. Ayres, \& C. M. Buchalla (Orgs.), Coletânea: Vulnerabilidade e Direitos Humanos. Prevenção e promoção da saúde: Vol. 1. Da doença à cidadania (pp. 9-22). Curitiba, PR: Juruá.

Ayres, J. R., Paiva, V., \& Franca, I., Jr. (2012). Conceitos e práticas de prevenção: Da História $\mathrm{Na}-$ tural da Doença ao Quadro da Vulnerabilidade e Direitos Humanos. In V. Paiva, J. R. Ayres, \& C. M. Buchalla (Orgs.), Coletânea: Vulnerabilidade e Direitos Humanos. Prevenção e promoção da saúde: Vol. 1. Da doença à cidadania (pp. 71-94). Curitiba, PR: Juruá. (Reproduzido a partir de Routledge Handbook of Global Public Health, Vol. 1, pp. 98-107, de R. Parker \& M. Sommer, Eds., 2010, London: Routledge)

Barbieri, T. (1991). Sobre la categoría género. Una introducción teórico-metodológica. In S. Azerêdo \& V. Stolcke (Coords.), Direitos reprodutivos (pp. 25-45). São Paulo, SP: Fundação Carlos Chagas.

Berkman, A., Garcia, J., Muñoz-Laboy, M., Paiva, V., \& Parker, R. (2005). A critical analysis of the Brazilian response to HIV/AIDS: Lessons learned for controlling and mitigating the epidemic in developing countries. American Journal of Public Health, 95(7).

Boal, A. (1975). Teatro do oprimido e outras poéticas politicas [Theatre of the Oppressed]. Rio de Janeiro, RJ: Civilização Brasileira.

Brah, A. (2006, jan./jun.). Diferença, diversidade, diferenciação. Cadernos Pagu, (26), 329-376.

Brown, P., Zavestoski, S., McCormick, S., Mayer, B., Morello-Frosch, R., \& Gasior Altman, R. G. (2004, January). Embodied health movements: New approaches to social movements in health Sociology. Health \& Illness, 26(1), 50-80.
Butler, J. (1997). The Psychic life of Power: Theories in subjection. Stanford, CA: Stanford University Press.

Cañón, O. E. (2008). Las huellas del sujeto en narrativas de autores construccionistas [Subject's tracks in the narratives of constructionista authors]. Revista Diversitas - Perspectivas em Psicologia, 4(2), 245-257.

Farr, R. (1998). As raízes da Psicologia Social Moderna. Petrópolis, RJ: Vozes.

Freire, P. (1973). Pedagogia do Oprimido. Rio de Janeiro, RJ: Paz e Terra. (Original publicado em 1968)

Frosh, S. (2013). Psychosocial Theory. In T. Teo (Ed.), Encyclopedia of Critical Psychology. New York: Springer.

Gadamer, H. G. (1997). Verdade e método: Traços fundamentais de uma hermenêutica filosófica. Petrópolis, RJ: Vozes.

Gagnon, J. (2006). Uma interpretação do desejo: Ensaios sobre o estudo da sexualidade. Rio de Janeiro, RJ: Garamond.

García, J., Muñoz-Laboy, M., Almeida, V., \& Parker, R. (2009). Local impacts of religious discourses on rights to express same-sex sexual desires in peri-urban Rio de Janeiro. Sexuality Research \& Social Policy, 6(3), 44-60.

Greco, D. B., \& Simão, M. (2007, July 21). Brazilian policy of universal access to AIDS treatment: Sustainability challenges and perspectives. AIDS (Suppl. 4), 37-45.

Gruskin, S., \& Tarantola, D. (2008). Universal Access to HIV prevention, treatment and care: Assessing the inclusion of human rights in international and national strategic plans. AIDS, 22(Suppl. 2), 123-32.

Gruskin, S., \& Tarantola, D. (2012). Um panorama sobre saúde e direitos humanos. In V. Paiva, J. R. Ayres, \& C. M. Buchalla (Orgs.), Coletânea: Vulnerabilidade e Direitos Humanos. Prevenção e promoção da saúde: Vol. 1. Da doença à cidadania (pp. 23-41). Curitiba, PR: Juruá.

Hogget, P. (2008). What's in a Hyphen? Reconstructing psychosocial studies. London: Palgrave.

Joint United Nations Program on HIV/AIDS. (2011, October). UNAIDS Terminology Guidelines. Retrieved October, 2011, from http://www.unaids. org/en/media/unaids/contentassets/documents/ unaidspublication/2011/JC2118_terminology-guidelines_en.pdf 
Kalichman, A., \& Diniz, S. (2009). AIDS treatment in Brazil: What kind of evidence do we need? The Lancet, 374(969), 1066.

Kerrigan, D., Wirtz, A., Baral, S., Decker, M., Murray, L., Poteat, T., \& Beyrer, C. (2013). The Global HIV Epidemics among Sex Workers. Washington, DC: World Bank.

Kippax, S., Stephenson, N., Parker, R. G., \& Aggleton, P. (2013, June 13). Between Individual Agency and Structure in HIV Prevention: Understanding the Middle Ground of Social Practice. American Journal of Public Health, 103(8), 1367-1375.

Leavell, H. R., \& Clark, E. G. (1958). Textbook of Preventive Medicine. New York: McGraw-Hill.

Malta, M., \& Beyrer, C. (2013). The HIV epidemic and human rights violations in Brazil. Journal of the International AIDS Society, 16, 18817. Retrieved from http://www.jiasociety.org/index. php/jias/article/view/18817

Mann, J., Gruskin, S., Grodin, M., \& Annas, G. (Eds.). (1999). Health and human rights: A reader. New York: Routledge.

Mann, J., \& Tarantola, D. J. (Eds.). (1996). AIDS in the world II. New York: Oxford University Press.

Mann, J., Tarantola, D. J., \& Netter, T. W. (Eds.). (1992). AIDS in the world. Cambridge, MA: Havard Universty Press.

Mann, J., Tarantola, D. J., \& Netter, T. W. (1997). A AIDS no mundo. Rio de Janeiro, RJ: Relume Dumará

Ministério da Saúde. (1993). Normas de atenção à saúde integral de adolescente: Vol. 1. Diretrizes gerais para atendimento de adolescentes. Acompanhamento do crescimento e desenvolvimento. Distúrbios da puberdade. Desenvolvimento psicológico do adolescente. Brasília, DF: Autor.

Ministério da Saúde. (2008). Portaria n ${ }^{\circ} 154$. Cria os Núcleos de Apoio à Saúde da Família/NASF. Brasília, DF: Autor.

Moffat, A. (1987). Psicoterapia do Oprimido. São Paulo, SP: Cortez.

Nunn, A. S., da Fonseca, E. M., Bastos, F. I., \& Gruskin, S. (2009). AIDS treatment in Brazil: Impacts and challenges. Health Affairs, 28(4), 1103-1113.

Oliveira, E. C., \& Araújo, M. F. (2012). Aproximações do Teatro do Oprimido com a Psicologia e o Psicodrama. Psicologia: Ciência e Profissão, 32(2), 340-355.

Paiva, V. (1996). Sexualidades adolescentes: Escolaridade e gênero, e o sujeito sexual. In R. Parker \& R. Barbosa (Orgs.), Sexualidades Brasileiras (Vol. 1, pp. 213-224). Rio de Janeiro, RJ: Relume-Dumará.

Paiva, V. (2002). Sem mágicas soluções: A prevenção e o cuidado em HIV/AIDS e o processo de emancipação psicossocial. Interface: Comunicação, Saúde e Educação, 6(11), 25-38.

Paiva, V. (2007). Gendered scripts and the sexual scene: Promoting sexual subjects among Brazilian Teenagers. In Culture, Society and Sexuality. $A$ reader $\left(2^{\text {nd }}\right.$ ed.). New York: Routledge.

Paiva, V. (2008). A psicologia redescobrirá a sexualidade? Psicologia em Estudo, 13, 641-651.

Paiva, V. (2012a). Cenas da Vida Cotidiana: Metodologia para compreender e reduzir a vulnerabilidade na perspectiva dos Direitos Humanos. In V. Paiva, J. R. Ayres, \& C. M. Buchalla (Orgs.), Coletânea: Vulnerabilidade e Direitos Humanos. Prevenção e promoção da saúde: Vol. 1 . Da doença à cidadania (pp. 165-208). Curitiba, PR: Juruá.

Paiva, V. (2012b). A dimensão psicossocial do cuidado. In V. Paiva, G. Calazans, \& A. Segurado (Orgs.), Coletânea: Vulnerabilidade e Direitos Humanos. Prevenção e promoção da saúde: Vol. 2. Entre indivíduos e comunidades (2. ed., pp. 41-72). Curitiba, PR: Juruá.

Paiva, V., Ayres, J. R., \& Franca, I., Jr. (2004, January). Expanding the flexibility of normative patterns in youth sexuality and prevention programs. Sexuality Research \& Social Policy, 1(1).

Parker, R., \& de Camargo, K., Jr. (2000). Pobreza e HIV/AIDS: Aspectos antropológicos e sociológicos. Cadernos de Saúde Pública, 16(1), 89102.

Pinheiro, R., \& Lopes, T. C. (Orgs.). (2010). Ética, técnica e formação: As razões do cuidado como direito à saúde. Rio de Janeiro, RJ: Centro de Estudos e Pesquisa em Saúde Coletiva.

Pinheiro, R., \& Mattos, R. A. (2006). Cuidado: As fronteiras da integralidade. Rio de Janeiro, RJ: Centro de Estudos e Pesquisa em Saúde Coletiva.

Pupo, L. R. (2012). As dimensões teórica, técnica e ético-operacional: Multidimensionalidade da ação preventiva e de cuidado à saúde. In V. Pai- 
va, G. Calazans, \& A. Segurado (Orgs.), Coletânea: Vulnerabilidade e Direitos Humanos. Prevenção e promoção da saúde: Vol. 2. Entre indivíduos e comunidades (2. ed., pp. 41-72). Curitiba, PR: Juruá.

Rother, E. T. (2007). Revisão sistemática X revisão narrativa. Acta Paulista de Enfermagem, 20(2), 5-6. Recuperado em 26 de setembro, 2013, de http://www.scielo.br/ scielo.php?script $=$ sci_arttext\&pid $=$ S0103$-21002007000200001 \& \operatorname{lng}=\mathrm{en} \& \mathrm{t} \operatorname{lng}=\mathrm{pt}$. 10.1590/S0103-21002007000200001

Santos, B. S. (2003). Reconhecer para libertar: Os caminhos do cosmopolitismo multi-cultural. Rio de Janeiro, RJ: Civilização Brasileira.

Santos, F. M., \& Jacó-Vilela, A. M. (2009, maio/ ago.). O psicólogo no hospital geral: Estilos e coletivos de pensamento. Paidéia (Ribeirão Preto), $19(43), 189-197$.

Scott, J. W. (1995, jul./dez.). Gênero: Uma categoria útil de análise histórica. Educação \& Realidade, 20(2), 71-99. (Revisão de T. T. da Silva a partir de Gender and the Politics of History, de J. W. Scott, 1988, pp. 28-50, New York: Columbia University Press)
Seffner, F., Paiva, V., \& Pupo, L. (2012). Educação em saúde e emancipação: Explorando possibilidades da prevenção no quadro dos direitos humanos In V. Paiva, L. Rivero Pupo, \& F. Seffner (Orgs.), Coletânea: Vulnerabilidade e Direitos Humanos - Prevenção e promoção da saúde: Vol. 3. Pluralidade de vozes e inovação de práticas (pp. 253-268.). Curitiba, PR: Juruá.

Silva, C. G., Santos, A. O., Licciardi, D. C., \& Paiva, V. (2008). Religiosidade, juventude e sexualidade: Entre a autonomia e a rigidez. Psicologia em Estudo, 13(4).

Simon, W., \& Gagnon, J. H. (1969). On psychosocial development. In D. A. Goslin (Ed.), Handbook of Socialization Theory and Research (pp. 733752). Chicago, IL: Rand McNally.

Spink, M. J. (2013). Psicologia Social e Saúde. Práticas, saberes e sentidos. Petrópolis, RJ: Vozes

Tunala, G. L. (2012). Modelos teóricos como subsídios da prática da promoção da saúde em DST/ Aids no quadro da vulnerabilidade e dos direitos humanos. In V. Paiva, G. Calazans, \& A. Segurado (Orgs.), Coletânea: Vulnerabilidade e Direitos Humanos. Prevenção e promoção da saúde: Vol. 2. Entre individuos e comunidades (2. ed.). Curitiba, PR: Juruá. 